\title{
Correlation between Clinical Findings in Patients with Breast Lump and Radiological and Pathological Finding
}

\author{
ASHRAF E. EL-SHARKAWY, M.D.*; RAGHEB A. RAGHEB, M.D.* and WAFAA Kh. TIR EL-BAR, M.Sc.** \\ The Department of General Surgery, Faculty of Medicine for Girls, Al-Azhar University* and \\ Faculty of Medicine, Menofia University**
}

\begin{abstract}
Background: Although the diagnosis of breast cancer is suggested on clinical examination, the degree of suspicion is variable. Currently a combination of three tests, i.e. clinica examination, radiological imaging (mammography, ultrasonography) and pathology called as triple assessment test is used to accurately diagnose all palpable breast lumps.
\end{abstract}

Aim of Study: Assessment for how much the clinical finding in patients with breast lumps correlates with radiological and pathological finding.

Patients and Methods: This study was carried out on 50 female patients who presented with breast lump in the outpatient clinics of Al-Zahraa University Hospital. Patients with a breast lump were selected irrespective of age. A detailed history, clinical examination, mammosonographic imaging and Fine-Needle Aspiration Cytology (FNAC) were used as diagnostic tools for screening of the patients.

Results: The sensitivity of clinical examination to detect malignant breast mass was $80 \%$, specificity was $100 \%$, Positive Predictive Value (PPV) was $100 \%$, Negative Predictive Value (NPV) $95.24 \%$ and with $96 \%$ accuracy. The sensitivity of mammosonography to detect malignant breast mass was $70 \%$, specificity was $100 \%$, positive predictive value $100 \%$, negative predictive value was $93.02 \%$ \& with $94 \%$ accuracy. The sensitivity of FNAC to detect malignant breast mass was $71.43 \%$, specificity was $100 \%$, positive predictive value was $100 \%$, negative predictive value was $95.24 \%$ \& with $95.24 \%$ accuracy.

Conclusion: This study revealed the accuracy of clinical examination, mammosonography \& FNAC in evaluating breast lump especially when applied together.

Key Words: Aspiration cytology - Fine-needle-Breast Carcinoma-Clinical examination - Ultrasonography - Mammography.

Correspondence to: Dr. Ashraf E. El-Sharkawy,

The Department of General Surgery,

Faculty of Medicine for Girls, Al-Azhar University

\section{Introduction}

BREAST cancer is the most frequent malignancy in women, with an incidence (wold-wide) of 3544 new cases per 100.000 women/per year. Detection and treatment of breast cancer have significantly improved over past decades, which results in higher survival rates [1]. The first step in evaluation of breast lump is the clinical assessment. Although many times clinician can confidently make the diagnosis of benign or malignant lesion, even in experienced hands the possibility of mistake is always there [2]

Mammography screens for occult malignancy in the same and contralateral breast and can detect malignant lesions in older women; but it is less sensitive in women younger than 40 years. Ultrasonography can detect cystic masses, which are common, and may be used to guide biopsy techniques. Tissue Specimens obtained with coreneedle biopsy permits histologic diagnosis, hormone-receptor testing, and differentiation between in situ and invasive disease. Core-needle biopsy is more invasive than fine-needle aspiration, requires more training and experience, and frequently requires imaging guidance. After the clinical breast examination is performed, the evaluation depends mostly on the patient's age and examination characteristics, and the physician's experience in performing fine-needle aspiration [3]

Triple test is a simple, safe, cost effective and rapid method depending upon which definitive treatment can be started [4].

\section{Patients and Methods}

This prospective study included 50 patients presented with breast lump in the outpatient clinics 
of Al-Zahraa University Hospital from October 2016 to October 2018. Patients were followed-up for a minimum of 3 months and a maximum of 6 months. Every patient was subjected to:

1- Full history taking: Including: Age, marital status, menstrual history, parity, lactation history, contraceptive history, onset, course and duration of the mas, assessment of: The lump, nipple discharge of the breast on both sides. Past history of: Breast cancer or complaint, breast or chest trauma. Family history of similar condition or breast cancer.

2- Examination of both breasts \& draining lymph nodes including axillary lymph and supraclavicular nodes.

3- Mammosonography examination.

4- Fine needle aspiration cytology.

\section{Results}

This prospective study included 50 patients who presented with breast lump, the age was ranged between 18 years and 70 years with a mean age of 40.82 years. Whereas the highest incidence $(28 \%)$ of breast lump occurred in the age group 25-35 years (Table 1).

Table (1): The age incidence among patients with breast lump.

\begin{tabular}{lcl}
\hline Age group & No. of cases & $\%$ \\
\hline From 18 to $<25$ & 4 & 8 \\
From 25 to $<35$ & 14 & 28 \\
From 35 to $<45$ & 12 & 24 \\
From 45 to $<55$ & 12 & 24 \\
From 55 to $<65$ & 7 & 14 \\
From 65 to $<75$ & 1 & 2 \\
\hline Total & 50 & 100 \\
\hline
\end{tabular}

Forty one cases ( $82 \%$ ) were married. (36 patients from the 41 married patients $(87.8 \%)$ were multiparous \& five patients were nulliparous $(12.2 \%)$ ), while nine cases (18\%) were unmarried. Twenty eight cases were from rural areas $(56 \%)$ and twenty two cases (44\%) from urban areas. Forty three cases $(86 \%)$ were having age of menarche 12 years or more, seven cases $(14 \%)$ were having age of menarche less than 12 years. Fourteen cases were postmenopausal (28\%), thirty six cases were premenopausal (72\%). Menstrual abnormalities were recorded in thirteen cases $(26 \%)$, six cases with menorrhagia $(12 \%)$, four cases $(8 \%)$ with irregular cycles and three cases $(6 \%)$ with amenorrhea. Thirty two cases (64\%) were lactating their infants up to 1 year. Twenty-five patients $(50 \%)$ were using contraceptive methods, twelve
$(48 \%)$ of them were using Oral Contraceptive Pills (OCPs), ten $(40 \%)$ of them were using Intrauterine Device (IUD), and three (12\%) were on contraceptive injection (Table 2).

Table (2): Clinical presentation.

\begin{tabular}{lcc}
\hline Complaint & $\begin{array}{c}\text { Number } \\
\text { of cases }\end{array}$ & $\%$ \\
\hline Breast, lump, mobile, painless & 24 & 48 \\
Breast lump with pain & 20 & 40 \\
Breast lump with pain and nipple discharge & 3 & 6 \\
Breast lump with retraction & 3 & 6 \\
\hline Total & 50 & 100 \\
\hline
\end{tabular}

In forty seven patients (94\%) the mass was unilateral, twenty seven of them in right side $(57.4 \%)$, twenty patients in left side $(42.6 \%)$ and in three patients $(6 \%)$ the mass was bilateral. The mass in the affected breast was central in six cases $(12 \%)$, upper outer quadrant in twenty four cases (48\%), upper inner quadrant in cases in eight cases $(16 \%)$, lower outer quadrant in seven cases $(14 \%)$ and lower inner quadrant in five cases $(10 \%)$. On palpation of the mass most of them were firm in consistency in thirty seven cases $(74 \%)$, firm with cystic areas in two cases (4\%), cystic in three cases $(6 \%)$ and hard in eight cases $(16 \%)$. The mass was painful in five cases $(10 \%)$. According to the BIRADS classification no cases were in category 0,1 \& 6.34 cases $(68 \%)$ diagnosed as category 2,9 cases $(18 \%)$ as category $3,4(8 \%)$ cases as category $4 \& 3$ cases $(6 \%)$ as category 5 (Table 3 ).

Fine needle aspiration biopsy was done for all cases, benign mass was found in 42 cases $(84 \%)$, suspicious or non-conclusive in 3 cases $(6 \%) \&$ malignant mass in 5 cases $(10 \%)$. Post-operative histopathological examination was done for all breast masses: Forty cases (80\%) of breast lumps proved to be benign: Twenty seven (54\%) cases were fibroadenoma, five cases $(10 \%)$ were fibrocystic changes, three cases $(6 \%)$ were fibroadenosis, one cases $(2 \%)$ was lipoma, two cases $(4 \%)$ were abscess $\&$ two cases $(4 \%)$ were Simple cyst. Ten cases $(20 \%)$ were malignant: Seven cases $(14 \%)$ were Invasive Duct Carcinoma (IDC), 2 cases (4\%) were Invasive Lobular Carcinoma (ILC) and one case $(2 \%)$ was mucinous carcinoma (Table 3$)$.

Table (3): Correlation between CE, imaging, FNAC \& postoperative histopathology.

\begin{tabular}{|c|c|c|c|c|c|c|c|c|}
\hline & \multicolumn{2}{|c|}{$\mathrm{CE}$} & \multicolumn{2}{|c|}{$\begin{array}{l}\text { Mammo- } \\
\text { sonograhy }\end{array}$} & \multicolumn{2}{|c|}{ FNAC } & \multicolumn{2}{|c|}{$\begin{array}{c}\text { Histo- } \\
\text { pathology }\end{array}$} \\
\hline & No. & $\%$ & No. & $\%$ & No. & $\%$ & No. & $\%$ \\
\hline Benign & 42 & 84 & 43 & 86 & 42 & 84 & 40 & 80 \\
\hline Malignant & 8 & 16 & 7 & 14 & 8 & 16 & 10 & 20 \\
\hline
\end{tabular}


By clinical examination 42 breast masses $(84 \%)$ were found to be benign, 40 masses of them proved to be benign by post-operative histopathological examination, while 2 masses proved to be malignant. Eight breast masses were diagnosed malignant by both clinical examination and post-operative histopathological examination.

Mammosonography examination revealed that 43 breast masses were benigin, of which 40 masses proved by post-operative histopathology to be benign while 3 masses proved to be malignant. 7 breast masses found to be malignant by both mammosonography \& post-operative histopathology examination.

42 breast masses ( $84 \%$ ) were benign by fine needle aspiration cytology, 40 of them proved to be benign by post-operative histopathology while 2 masses proved to be malignant. 3 breast masses (6\%) were suspicious by FNAC examination and proved to be malignant by post-operative histopathology. 5 breast masses (10\%) were malignant by both fine needle aspiration cytology and postoperative histopathology (Table 4).
The sensitivity of clinical examination to detect malignant breast mass was $80 \%$, specificity was $100 \%$, positive predictive value was $100 \%$, negative predictive value $95.24 \%$ and with $96 \%$ accuracy. The sensitivity of mammosonography to detect malignant breast mass was $70 \%$, specificity was $100 \%$, positive predictive value $100 \%$, negative predictive value was $93.02 \%$ \& with $94 \%$ accuracy. The sensitivity of fine needle aspiration cytology to detect malignant breast mass was $71.43 \%$, specificity was $100 \%$, positive predictive value was $100 \%$, negative predictive value was $95.24 \%$ \& with $95.24 \%$ accuracy (Table 4 ).

Table (4): Comparison between CE, imaging \& FNAC.

\begin{tabular}{llcc}
\hline & CE & Mammosonography & FNAC \\
\hline Sensitivity & $80 \%$ & $70 \%$ & $71.43 \%$ \\
Specificity & $100 \%$ & $100 \%$ & $100 \%$ \\
PPV & $100 \%$ & $100 \%$ & $100 \%$ \\
NPV & $95.24 \%$ & $94 \%$ & $95.24 \%$ \\
Accuracy & $96 \%$ & $93.02 \%$ & $95.24 \%$ \\
\hline
\end{tabular}
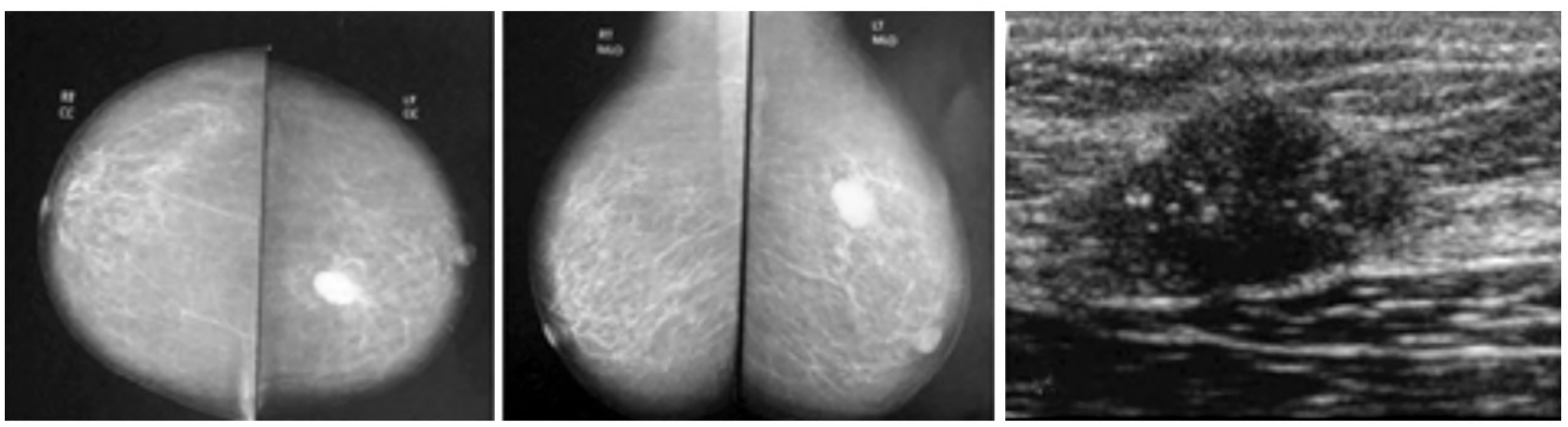

Fig. (1): Infiltrating duct carcinoma: A \& B Bilateral mammogram showing speculated mass BI-RADS (4) with bilateral axillary reactive lymphadenopathy. C) Ultrasound mammogram showing infiltrating ductal carcinoma with an ill-defined hypoechoic mass with microcalcifications, BI-RADS (4).

\section{Discussion}

Breast lesions are commonly encountered in surgical pathology. With increasing incidence of carcinoma of breast, high level of pre-operative diagnostic accuracy has become highly imperative. The highest level of pre-operative diagnostic accuracy of breast lesions can be achieved using a triple approach. This concept combines the results of imaging, clinical examination and FNAC [4]

This study included 50 female patients with breast lump; the age of patients presented with breast lump ranged between 18 years and 70 years with a mean age of 40.82 years. Whereas the highest incidence (28\%) of breast lump occurred in the age group 25-35 years. This finding correlates with the results of Bhavinder, [6] who had studied 50 patients attending outpatient department for a palpable breast lump, the age of the patients ranged from 29 to 75 years, with a mean age of 42.1 years. Also Al-Alwan, [7] found that the mean age of patients was (42.6) years with age ranged from (20-76) years in his study on 60 patients with breast lump. While the age of the patients ranged from 35 to 86 years with mean age of $49 \pm 4.2$ in Sarangan et al., [8] in their prospective study which was conducted over a period of 5 months. A total of 50 patients with suspicious breast mass were evaluated with cytology and sonomammography.

In our study, forty one cases (82\%) were married [thirty six patients from the forty one married patients $(87.8 \%)$ were multiparous $\&$ five patients 
were nulliparous $(12.2 \%)]$, while nine cases $(18 \%)$ were unmarried. Twenty eight cases were from rural $(56 \%)$, twenty two cases (44\%) from urban areas. Forty three cases $(86 \%)$ were having age of menarche 12 years or more, seven cases $(14 \%)$ were having age of menarche less than 12 years. Fourteen cases were postmenopausal (28\%), thirty six cases were premenopausal (72\%). Menstrual abnormalities were recorded in thirteen cases (26\%), six cases with menorrhagia, four cases with irregular cycles and three cases with amenorrhea. Thirty two cases (64\%) were lactating their infants up to 1 year. Twenty-five patients $(50 \%)$ were using contraceptive methods, twelve $(48 \%)$ of them were using OCPs, ten $(40 \%)$ of them were using IUD, and three (12\%) were on contraceptive injection.

This is correlates with Masooda et al., [9] in their study on 200 patients with a breast lump attended to the OPD over a period of 3 years from June 2005 to May 2008: Of the studied patients $139(69.5 \%)$ were married and the rest were unmarried. Of the married patients $131(94.2 \%)$ were multiparous and $8(5.8 \%)$ were nulliparous. 150 patients $(75 \%)$ were from rural while 50 patients (25\%) were from urban. One hundred and seventytwo $(86 \%)$ patients were having age of menarche $>12$ years. $28(14 \%)$ patients had age of menarche. 177 patients $(88.5 \%)$ were premenopausal and 23 $(11.5 \%)$ patients were postmenopausal.

In our study, according to the BI-RADS classification no cases were in category $0,1 \& 6.34$ cases $(68 \%)$ diagnosed as category 2,9 cases $(18 \%)$ as category $3,4(8 \%)$ cases as category $4 \& 3$ cases (6\%) as category 5. In Navya et al., [10] study the results of sonomammogram according to BIRADS classifications were: There were no patients in categories 0,1 and 6 . There were 14 patients $(28 \%)$ in category 2 revealing benign findings, 16 patients ( $32 \%$ ) in category 3 revealing probably benign finding, 10 in category $4(20 \%)$ revealing suspicious abnormality and 10 patients in category 5 (20\%) indicating a high suspicion of malignancy. While Shrestha et al., [11] study found that 14 cases were category 0,50 cases were category 1,80 cases were category 2,14 cases were category 3,11 cases were category 4 , cases category $5 \&$ no cases category 6 in their combined retrospective and prospective study on 173 patients with breast symptoms.

Fine needle aspiration cytoloigy was done for all cases, benign mass was found in 42 cases $(84 \%)$, suspicious or non-conclusive in 3 cases $(6 \%) \&$ malignant mass in 5 cases (10\%). In contrast of
Farzana et al., [12] results of FNAC were benign in 9 cases, confirmed carcinoma in 14 cases, suspicious in 21 cases, atypia in 7 cases $\&$ the sample was inadequate in 1 case. Similarly, Ganiat et al., [13] studied 757 cases on FNAC and found that the majority of cases were benign (50.2\%), which was followed by malignant cases $(31.4 \%)$, suspicious malignant cases $(9.5 \%)$ and inflammatory cases (7.4\%). Unlike Pattari et al., [14] studied 71 histologically confirmed cases and documented infiltrating ductal carcinoma as the most common lesion (24/71).

In our study all breast masses were excised and sent for histopathological examination. Forty cases $(80 \%)$ of breast lumps proved to be benign: Twenty seven $(54 \%)$ cases were fibroadenoma, five cases $(10 \%)$ were fibrocystic changes, three cases $(6 \%)$ were fibroadenosis, one cases (2\%) was lipoma, two cases $(4 \%)$ were abscess \& two cases $(4 \%)$ were simple cyst. Ten cases $(20 \%)$ were malignant: Seven cases (14\%) were IDC, 2 cases (4\%) were ILC \& one case ( $2 \%$ ) was mucinous carcinoma. Out of 50 patients in Amandeep et al., [15] study the histological examination revealed fibroadenoma: 7 cases (14\%), fibroadenosis; 2 cases $(4 \%)$, fibrocystic disease: 5 cases (\%10), inflammatory: 1 case (\%2), intraductal papilloma: 1 case (\%2), sclerosing adenosis: 1 case (2\%), duct ectasia: 1 case (\%2), Infilterating Ductal Carcinoma (IDC): 29 cases $(58 \%)$, invasive lobular carcinoma: 2 cases (4\%) mucinous carcinoma: 1 case (2\%). These findings are similar to the study of Khokher et al., [16] in which infilterating ductal carcinoma was found in $91 \%$ of the total malignant cases followed by lobular carcinoma and then by mucinous carcinoma.

By clinical examination 42 breast masses (84\%) found to be benign, 40 masses of them proved to be benign by post-operative histopathological examination, while 2 masses proved to be malignant. Eight breast masses were found malignant by both clinical examination $\&$ post-operative histopathological examination.

In our study the sensitivity of clinical examination to detect malignant breast mass was $80 \%$, specificity was $100 \%$, positive predictive value was $100 \%$, negative predictive value $95.24 \%$ and with $96 \%$ accuracy. Studies assessing CBE as part of triple assessment have shown variable sensitivity and specificity. Two studies of Morris et al., [17], Ravi \& Rodrigues [18] showed higher sensitivity $(87 \%)$ and lower specificity $(80 \%)$. In a study of Afsheen, [19] the sensitivity of CE to detect malignant mass was $100 \%$, specificity was $95 \%$ \& NPV 
was $100 \%$. While another study done by Jan et al., [20] showed PPV of $80 \%$, NPV 99.3\%, sensitivity of $92.3 \%$ and specificity of $97.8 \%$.

Mammosonography examination revealed that 43 breast masses were benign, of which 40 masses proved by post-operative histopathology to be benign while 3 masses proved to be malignant. 7 breast masses found to be malignant by both mammosonography \& post-operative histopathology examination.

In this study, the sensitivity of mammosonography to detect malignant breast mass was $70 \%$, specificity was $100 \%$, positive predictive value $100 \%$, negative predictive value was $93.02 \% \&$ with $94 \%$ accuracy. The sensitivity was $95.7 \%$, specificity was $89.2 \%$, NPV was $99.9 \%$ \& PPV was $13.2 \%$ in Lehman et al., [21] study. While Li et al., [22] in their retrospective study reported that the sensitivity in detecting malignant mass was $97.9 \%$ \& specificity was $49.7 \%$. In Houssami et al., [23] retrospective study the sensitivity was $81.7 \%$ \& specificity was $88 \%$.

In our study, 42 breast masses $(84 \%)$ were benign by fine needle aspiration cytology, 40 of it proved to be benign by post-operative histopathology while to masses proved to be malignant. 3 breast masses $(6 \%)$ were suspicious which proved to be malignant by post-operative histopathology. 5 breast masses (10\%) were malignant. The sensitivity of fine needle aspiration cytology to detect malignant breast mass was $71.43 \%$, specificity was $100 \%$, positive predictive value was $100 \%$, negative predictive value was $95.24 \%$ \& with $95.24 \%$ accuracy. This correlates with Ajitha et al., [24] out of a total 70 breast lump aspirations, 36 breast lumps were benign and 34 breast lumps were malignant lumps. FNAC sensitivity was $86.84 \%$, specificity was $100 \%$, PPV was $100 \%$, NPV was $86.49 \%$. A number of publications have demonstrated the high overall accuracy of FNA in the diagnosis of breast lesions. A large-scale study of 2,375 lesions from Thailand done by Chaiwun et al., [25] showed sensitivity, specificity, positive predictive value, and negative predictive values of $84.4 \%, 99.5 \%$, $99.8 \%$, and $84.3 \%$, respectively \& overall diagnostic accuracy of $91.3 \%$. Combined with more recent studies, Mizuno et al., [26], the overall sensitivity was $76-99 \%$, specificity $60-100 \%$, positive predictive value $94-100 \%$, negative predictive value $67-$ $96 \%$, diagnostic accuracy $72-95 \%$.

Many studies evaluate the triple test for assessment of breast lumps. Thomas et al., [27] reported that sensitivity, specificity, negative and positive predictive values, and accuracy of mammography were $77.6 \%, 98.8 \%, 99.8 \%, 35.8 \%$, and $98.6 \%$, respectively; those of $\mathrm{PE}, 27.6 \%, 99.4 \%, 99.4 \%$, $28.9 \%$, and $98.8 \%$, respectively; and those of US, $75.3 \%, 96.8 \%, 99.7 \%, 20.5 \%$, and $96.6 \%$, respectively.

\section{Conclusion:}

Clinical examination, mammo sonography \& FNAC are good tests for diagnosis of breast lumps. All the patients complaining of breast lumps should undergo a triple assessment to make an early \& accurate diagnosis.

\section{References}

1- BERRY A., CRONIN A., PLEVRITIS K., et al.: Effect of Screening and Adjuvant Therapy on Mortality from Breast Cancer. New England Journal of Medicine, 353: 1784-92, 2005.

2- RONAK C., SAMIR R. and ASHAR S.: Diagnostic Approach to Palpable Breast Lump-A Quadruple Assessment. International Journal of Science and Research, 6 (5): 2571-87, 2017.

3- SUSAN K.: Evaluation of Palpable Breast Masses. American Family Physician, 71 (9): 1731-8, 2005.

4- ASHWINKUMAR S.G., UDIT I.G., DHAVAL A.B., et al.: Role of triple assessment modalities in diagnosis of palpable breast lump. J. Res. Med. Sci., 6 (10): 3435-40, 2018.

5- AHMED N., CHAUDHARY M.Y. and KUNDI S.: Triple Assessment of breast lump. J. Coll. Physicians. Surg. Pak., 17 (9): 535-8, 2007.

6- BHAVINDER A.: Triple assessment for breast lump diagnosis in outpatient department. I.J.S.R., 5 (2): 2913, 2016.

7- AL-ALWAN M.H.: The Role of double test: Physical examination and fine needle aspiration cytology in the management of breast diseases. J. F. B. Med., 43: 9-12, 2001.

8- SARANGAN A., GEETHA R., SAHAYA R., et al.: Study of histopathological correlation of breast mass with radiological and cytological findings. IOSR Journal of Dental and Medical Sciences, 16 (3): 4: 1-7, 2017.

9- FARZANA M., SAJIDA Q., MOHAMUD Z., et al.: Sensitivity of fine needle aspiration vs core biopsy in diagnosis of palpableand clinical suspicious breast lesion. Pak. J. Surg., 25 (3): 214-7, 2009.

10- MASOODA J., JAVEED A.M., NAZIR A., et al.: Triple assessment in the diagnosis of breast cancer in Kashmir. Indian J Surg., 72: 97-103, 2010.

11- NAVYA B.N., SHALU T., RUDRESH H., et al.: Comparison of Diagnostic Accuracy of BIRADS Score With Pathologic Findings in Breast Lumps. Annals of Pathology and Laboratory Medicine, 4 (3): 235-42, 2017.

12- SHRESTHA M.K., GHARTIMAGAR D., GHOSH A., et al.: Significance of Quadruple assessment of breast lumpA hospital based Study. J. N. Path., 4: 630-4, 2014. 
13- PATTARI S.K., DEY P., GUPTA S.K., et al.: Myoepithelial cells: Any role in aspiration cytology smears of breast tumours? Cytojournal, 5: 9, 2008.

14- GANIAT O., OMONIYI-ESAN G., OSASAN S., et al.: Cytopathological review of breast lesions in Ile-Ife Nigeria. The Internet J. of Third World Med., 8: 1025, 2008.

15-AMANDEEP S., SOFIA A. and NEKIINT N.S.: Diagnostic accuracy of triple assessment in palpable breast lump. J. Curr. Res. Med. Sci., 3 (6): 1-8, 2017.

16- KHOKHER S., QURESHI M.U., RIAZ M., et al.: Clinicopathologic Profile of Breast Cancer Patients: Ten Years Data of a Local Cancer Hospital. Asian Pacific J. Cancer Prev., 13: 693-9, 2013.

17- MORRIS K.T., POMMIER R.F., MORRIS A., et al.: Usefulness of the triple test score for palpable breast masses. Arch. Surg., 136: 1008-13, 2001.

18- RAVI C. and RODRIGUES G.: Accuracy of clinical examination of breast lumps in detecting malignancy: A retrospective study. Indian J. Surg. Oncol., 3 (2): 154-7, 2012.

19- AFSHEEN Z.: Clinical breast examination; the diagnostic accuracy in palpable breast lumps. Professional Med. J., 21 (6): 1147-52, 2014.

20- JAN M., MATTOO J.A., SALROO N.A., et al.: Triple assessment in the diagnosis of breast cancer. Indian J. Surg., 72: 97-103, 2010

21- LEHMAN C.D., LEE C.I., LOVING V.A., et al.: Accuracy and value of breast ultrasound for primary imaging eval- uation of symptomatic women 30-39 years of age. A.J.R. Am. J. Roentgenol., 199 (5): 1169-77, 2012.

22- LI J., XING P., FENG L., et al.: The value of sub-stratified combined imaging assessment with mammography and ultrasonography for Chinese women with palpable breast masses. Breast Cancer Res. Treat., 144 (2): 391-6, 2014.

23- HOUSSAMI N., IRWIG L., SIMPSON J.M., et al.: Breast Imaging Accuracy Study: Comparative sensitivity and specificity of mammography and sonography in young women with symptoms. A.J.R. Am. J. Roentgenol., 180 (4): 935-40, 2003.

24- AJITHA M.B., VINOD B.B. and AVINASH C.S.: Comparative study of fine needle aspiration cytology, true cut biopsy and final histopathological examination in breast lumps. International Journal of Biomedical Research, 8 (3): 154-7, 2017.

25- CHAIWUN B., SETTAKORN J., YA-IN C., et al.: Effectiveness of fine-needle aspiration cytology of breast: analysis of 2,375 cases from northern Thailand. Diagn. Cytopathol., 26 (3): 201-5, 2002.

26- MIZUNO S., ISAJI S., OGAWA T., et al.: Approach to fine needle aspiration cytology-negative cases of breast cancer. Asian J. Surg., 28 (1): 13-7, 2005.

27- THOMAS K., JACOB L. and JEFFREY H.: Newhouse. Comparison of the Performance of Screening Mammography, Physical Examination, and Breast US and Evaluation of Factors that Influence Them: An Analysis of 27,825 Patient Evaluations. Radiology, 225 (1): 14-6, 2002.

\section{مقارنة بين نتائج الفحص السريرى لحالات وجود كتلة بالثدى ونتائج الإشعات والتحاليل}

$$
\text { إن سرطان الثىى من الصعب الآمراض التى تصيب النساء المصريات ويشكل وج٪ من حالات المعهد القومى اللسرطان. }
$$

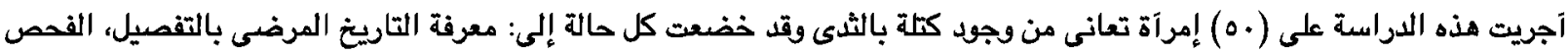

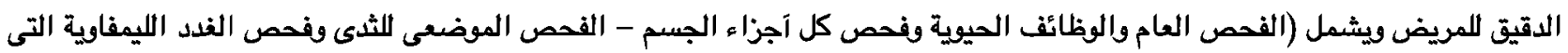

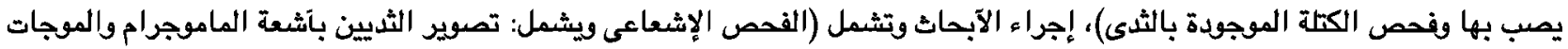

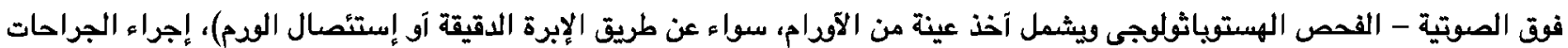

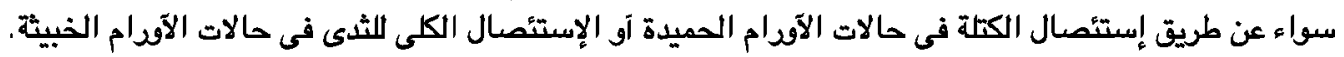

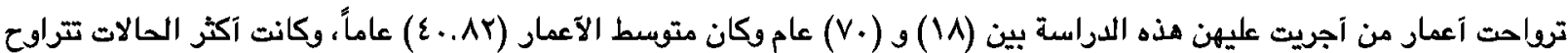

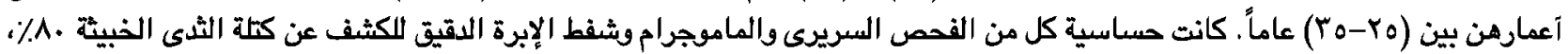

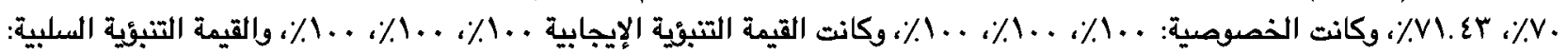

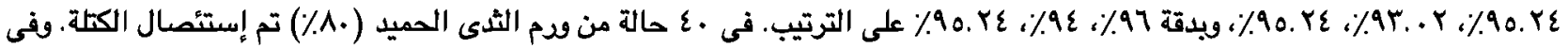

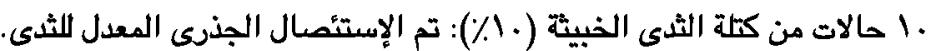

مما سبق يتضح لنا: إن طريقة واحدة لا تكفى لتشخيص آسباب كتل الثدى المختلفة ولكن لابد من إستخدام التقييم الثلاثى: التشخيص

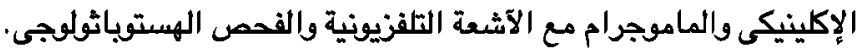

